\title{
Evaluating the Pharmaceutical Industry Interface with Managed Care
}

\author{
Kirk H. Hoffman
}

Ashok K. Gumbhir

\section{OBJECTIVE:}

To study the role of pharmaceutical sales representatives (PSRs) in the managed care environment, the value of support services and other benefits provided by industry, and the types of information needed by managed care organizations.

\section{DESIGN:}

Mailed survey.

\section{SETTING:}

Not applicable.

\section{PARTICIPANTS:}

500 members of the Academy of Managed Care Pharmacy.

\section{INTERVENTIONS:}

Mail questionnaires with more than 100 items using a five-point Likert scale and open-ended questions.

\section{MAIN OUTCOME MEASURES:}

Means and standard deviations analyzed with Student's $t$ test for paired data; nominal variables analyzed with chi-square analysis; and ordinal data analyzed using the Mantel-Haenszel test for linear association.

\section{RESULTS:}

Overall, 170 of 500 questionnaires (34\%) were completed and returned. Managed care pharmacists and industry executives agreed that drug sampling should be discontinued. In addition, they agreed on the order of importance of various support services, the types of research studies that are needed most, and the types of representatives who should call on managed care pharmacists. However, the two groups did not agree on the frequency with which PSRs currently interact with managed care pharmacists. In addition, $70 \%$ of the industry executives and only $5 \%$ of pharmacists

\begin{abstract}
believed that PSRs do not call on managed care physicians often enough. Of industry executives, $90 \%$ felt that the preferred type of representative to interact with managed care physicians was the traditional sales representative (versus $29 \%$ of managed care pharmacists with this opinion).
\end{abstract}

\section{CONCLUSION:}

Although managed care pharmacists and industry executives have similar opinions on many issues, their opinions diverge in several other areas.

\section{KEY WORDS:}

Managed care pharmacists, Pharmaceutical industry, Academy of Managed Care Pharmacy, Pharmaceutical marketing.

J Managed Care Pharm 1995: 1: 35-39.
The U.S. pharmaceutical industry is undergoing major restructuring and change in an attempt to deal with global markets, harmonization of international drug regulations, generic competition, and the movement of U.S. healthcare delivery from the traditional fee-for-service system to a managed healthcare environment. Pharmaceutical companies recognize that their primary customers are no longer individual physicians but rather buying groups representing large managed care or government patient populations.

In 1993, nearly 50 million Americans were enrolled in health-maintenance organizations, and an additional 77 million workers were eligible to use preferred-provider or- ganizations. ${ }^{1,2}$ Identifying and understanding the needs of managed care pharmacists is critical for the pharmaceutical industry as it restructures its marketing and research organizations and reallocates funding of these areas.

In the traditional marketplace, pharmaceutical companies employed large sales forces to promote their products and provide services to individual physicians and pharmacists. Recognizing the shift from the traditional marketplace to the managed care environment, considerable downsizing of sales forces has already occurred. ${ }^{3}$ However, what specifically will be the role of the pharmaceutical sales representative (PSR) in the managed care environment? In the

Authors

KIRK H. HOFFMAN, PH.D., R.PH., is Manager, Global Medical Product Surveillance, Marion Merrell Dow, Inc., Kansas City

ASHOK K. GUMBHIR, PH.D., R.PH., is Professor of Pharmacy Administration, School of Pharmacy, University of Missouri-Kansas City, Kansas City.

REPRINTS: Dr. Gumbhir, School of Pharmacy (107 KPB), University of Missouri-Kansas City, Kansas City, MO 64110.

ACKNOWLEDGMENTS: To members of the doctoral committee for their assistance with this project: Mark Quigley, Ph.D., Jean Paul Gagnon, Ph.D., Wayne Brown, Ph.D., and Phil Olson, Ph.D. 
traditional marketplace, hospital pharmacy directors and sales directors of pharmaceutical companies perceived the role of PSRs and level of satisfaction with PSRs very differently. ${ }^{4}$ In this study, $53 \%$ of the sales directors believed that PSRs were meeting $80 \%$ or more of the pharmacy directors' needs, whereas only $10 \%$ of the pharmacy directors agreed. Do these differing opinions also exist in the managed care marketplace?

Managed care pharmacists are increasingly requesting cost-effectiveness data from the pharmaceutical industry.

However, several areas are unclear:

$\nabla$ What type of data are needed?

$\nabla$ When are the data needed?

$\nabla$ How should the data be obtained?

$\nabla$ Who should develop the data?

$\boldsymbol{\nabla}$ Who should pay for the studies?

Lastly, the pharmaceutical industry provides a multitude of support services to their customers, such as continuing education, patient education materials, and drug information services. How important are these services to managed care pharmacists?

This study was undertaken to identify the needs of managed care pharmacists in five areas (PSR roles, professional journal advertising, direct-to-consumer advertising, research strategies, and value of support services) and to evaluate how well marketing executives of pharmaceutical companies understand these needs. The data pertaining to journal advertising and direct-to-consumer advertising are not presented in this paper.

\section{OBJECTIVES}

The objective of this study was to compare the perceptions of managed care pharmacists and marketing executives of pharmaceutical companies responsible for managed care markets regarding current and future services, marketing practices, and drug-development strategies of pharmaceutical companies. Areas of agreement and potential conflict between managed care pharmacists and industry executives were examined, primarily based on the differences in opinions and perceptions of the two groups.

\section{METHODS}

Questionnaire A mail questionnaire consisting of more than 100 questions was used to elicit opinions from managed care pharmacists and industry executives regarding the following subjects: (1) the role of PSRs, (2) professional journal advertising of prescription drugs, (3) direct-to-consumer prescription drug advertising, (4) research and new drug development, and (5) services or benefits provided by the drug industry. (Sections 1,4 , and 5 are presented in this paper.)

Items Five-point Likert scales were used to measure levels of agreement, importance, or frequency of occurrence. Several open-ended questions were used to encourage the respondent to state freely their opinions. The questionnaire was pretested. and modified based on the comments received. A prepaid, return envelope and cover letter explaining the purpose of the study and ensuring confidentiality accompanied each ques- tionnaire. A follow-up postcard and a second cover letter with replacement questionnaire were sent to nonresponders 15-21 days and 28 days, respectively, following the initial mailing. Statistical Analysis Frequent distributions and crosstabulations were prepared for all nominal and ordinal data. Differences between observed and expected frequencies of nominal variables were evaluated using chi-square analysis. All ordinal data were analyzed using the Mantel-Haenszel test for linear association. Means and standard deviations were calculated on all ordinal and interval variables; the Student's $t$ test for paired data was used to evaluate differences between the mean responses. Significance levels were set at $\alpha=0.05$ using twotailed tests

Participants All survey participants (managed care pharmacists and industry executives) were currently members of the Academy of Managed Care Pharmacy. AMCP members were used in this study for the following reasons: (1) pharmacists belonging to this association tend to be those practicing in managed care environments and (2) industry executives who are members of AMCP tend to be sales or marketing executives responsible for the managed care marketplace in their companies. Systematic, random samples of 300 pharmacists and 200 industry executives were selected for inclusion in this investigation.

\section{RESULTS AND DISCUSSION}

A $34 \%$ response rate was achieved for both the pharmacist and industry groups. No statistically significant differences were found between the two groups with respect to age, gender, or years of experience in pharmacy.

Of the pharmacists who responded, $79 \%$ were involved in making formulary decisions in their organization, with a majority $(73 \%)$ holding management positions. Most industry executive respondents (85\%) claimed full or partial responsibility for setting their company's managed care marketing strategy and more than $90 \%$ had sales and/or marketing backgrounds. Areas of agreement and disagreement between the groups regarding the three topics are presented bèlow.

\section{Areas of Agreement}

\section{Services Provided by Pharmaceutical Sales}

Representatives To determine whether PSRs are currently providing managed care pharmacists with the type of support needed, the study participants were asked to rate the importance of 10 different services often provided by PSRs. Table 1 presents the mean scores in descending order of importance by respondent type.

While mean scores were higher for industry executives for most of the services, overall, pharmacists and industry executives similarly rated the services in order of importance. The services considered most important by both groups included the ability to negotiate contracts, provide economic or outcomes data, and provide information on new drugs. Similarly, both managed care pharmacists and industry executives agreed that providing drug samples was the least important service and frequently mentioned that sampling, the use of 


\begin{tabular}{lcc} 
& \multicolumn{2}{c}{ Mean (no. Responses) $^{\mathrm{a}}$} \\
PSR Services & Managed Care Pharmacists & Industry Executives \\
\hline Distribute product health economic/outcomes data & $4.1(96)$ & $4.0(98)$ \\
Provide information on new drugs & $4.0(95)$ \\
Negotiate contracts/pricing & $3.7(97)$ \\
Support continuing education programs through independent groups & $3.4(96)$ \\
Support independent research & $3.3(98)$ \\
Provide information on established drugs & $2.6(89)$ \\
Handle outdated or damaged products or drug recalls & $2.4(89)$ \\
Resolve backorder problems, placing orders & $2.0(68)^{\mathrm{C}}$ \\
Provide samples as "starter" medications & $2.2(91)$ \\
Provide samples to encourage use of drug & $2.0(92)$ \\
\hline
\end{tabular}

${ }^{a}$ Importance was ranked on a five-point Likert scale with $l$ as low and 5 as high.

b Pharmacists' and executives' opinions significantly different at $=p<0.05$.

c Pharmacists' and executives' opinions significantly different at $=p<0.01$.

Table 2. Preferred Type of Representative to Interact with Managed Care Pharmacists

\begin{tabular}{lcc}
\hline & \multicolumn{2}{c}{ \% Favoring } \\
\cline { 2 - 3 } Type of Representative & $\begin{array}{c}\text { MC Pharmacists } \\
(\boldsymbol{n = 1 0 0 )}\end{array}$ & $\begin{array}{c}\text { Industry Executives } \\
(\boldsymbol{n}=\mathbf{6 8 )}\end{array}$ \\
\hline Traditional representative & 19.0 & 17.6 \\
Account manager & $76.0^{\mathrm{a}}$ & $94.1^{\mathrm{a}}$ \\
Professional liaison & 74.0 & 76.5 \\
Product economics manager & 73.0 & 83.8 \\
\hline
\end{tabular}

a Significant difference between pharmacists and executives at $=p<0.01$.

Table 3. Types of Research Studies Needed Most When Making Formulary Decisions

\begin{tabular}{lccc}
\hline & \multicolumn{2}{c}{ Mean Responses } \\
\cline { 2 - 4 } Type of Study & $\begin{array}{c}\text { MC } \\
\text { Pharmacists } \\
(\boldsymbol{n = 9 8 )}\end{array}$ & $\begin{array}{c}\text { Industry } \\
\text { Executives } \\
(\boldsymbol{n}=\mathbf{6 7 )}\end{array}$ & PValue \\
\hline Clinical efficacy studies & 2.0 & 1.9 & 0.848 \\
Outcomes studies & 2.3 & 2.7 & $0.020^{b}$ \\
Cost-effectiveness studies & 3.1 & 2.918 & 0.206 \\
Epidemiology/safety studies & 3.4 & 3.1 & 0.065 \\
Quality-of-life studies & 4.1 & 4.2 & 0.620 \\
\hline
\end{tabular}

a Need was ranked on a five-point Likert scale with 1 as needed most and 5 as needed least.

b Significant difference between pharmacists and executives.

gifts, give-aways, free meals, and traditional detailing should be discontinued.

A total of $50 \%$ of the pharmacists and $61 \%$ of the industry executives agreed or strongly agreed that PSRs can influence formulary decisions. This difference was not statistically significant $(p=0.21)$.

\section{Types of Pharmaceutical Representatives} Preferred by Managed Care Pharmacists In addition to the traditional.PSR, pharmaceutical companies are developing specialized representatives such as account managers, professional liaison representatives, and product economic managers to meet the needs of different types of managed care customers (e.g., physician, pharmacist, benefits manager). As shown in Table 2, the results of this survey indicate that both pharmacists and industry executives generally support the use of account managers, professional liaison representatives, and product economic managers to interact with managed care pharmacists. Both groups believe that the traditional type of representatives should not perform this specialized function.

Types of Research Needed in the Managed Care Environment The types of research studies needed most in the managed care environment (when making formulary decisions about new drugs being introduced to market) were also evaluated. As shown in Table 3, the order of importance or need, based on mean scores, was identical for managed care pharmacists and industry executives.

Pharmacoeconomic studies are an added expense in the development of a new drug. The respondents were asked to indicate which institutions (i.e., academia, managed care organizations, government, or pharmaceutical companies) should assume responsibility for funding these studies. The respondents were allowed to select more than one source of funding. Eighty-nine percent of pharmacists and $97 \%$ of industry executives responded that pharmaceutical companies should help pay for these studies. Managed care organizations should also pay for studies, according to $73 \%$ of the industry executives; significantly fewer of the pharmacists (46\%) agreed with this statement $(p<0.001)$. Other sources of funding suggested by the respondents included patients, insurance companies, employer groups, and physician networks.

Another question sought to clarify the role of the pharmaceutical industry in conducting pharmacoeconomic studies. A majority of pharmacists ( $72 \%$ ) and industry executives (62\%) believed that the pharmaceutical industry should serve only in a consultative role in conducting pharmacoeconomic studies. But $16 \%$ of pharmacists and $36 \%$ of industry executives believed that the pharmaceutical industry should have full responsibility for conducting these studies $(p=0.002)$.

\section{Support Services and Benefits Provided by} Pharmaceutical Companies The importance of 13 support services and benefits often provided by pharmaceutical companies to managed care health professionals were rated by 
Table 4. Importance of Support Services and Benefits Provided by Pharmaceutical Companies

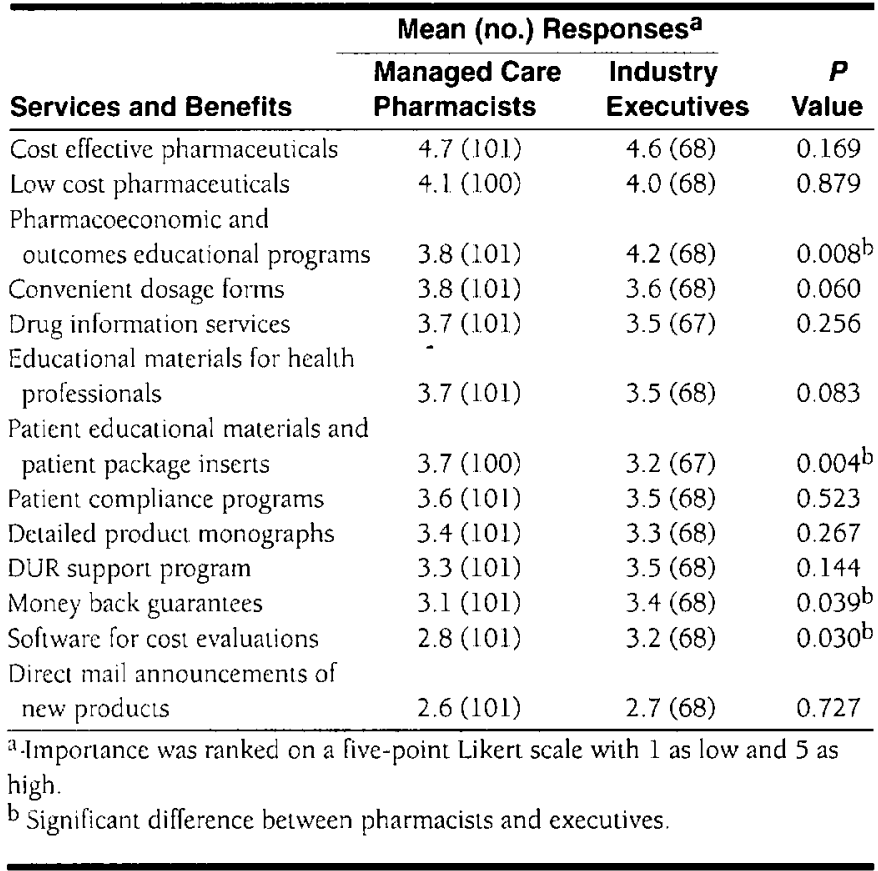

the two study groups. Mean scores for each service/benefit by respondent type are shown in Table 4. Managed care pharmacists and industry executives agreed on the importance of nine of the 13 support services or benefits.

More than $80 \%$ of the respondents indicated that the value of these services and benefits would be or possibly would be considered in the decision-making process. There was no significant difference between the two groups' responses on this issue.

The participants were asked whether drug companies should provide or financially support continuing education for physicians and pharmacists in managed care organizations. Responses between the two groups were not significantly different, with $79 \%$ of pharmacists and $84 \%$ of industry executives agreeing with this statement.

\section{Areas of Disagreement}

\section{Frequency of Pharmaceutical Sales}

Representative Visits To evaluate opinions regarding the frequency with which PSRs should contact managed care pharmacists, industry executives were asked how many PSRs they thought a managed care pharmacist sees each week. The pharmacist participant was asked how many PSRs they actually see each week. A follow-up question to both groups then asked whether they thought that the number of PSRs seen each week was about right, too few, or too many (Figures 1 and 2).

A majority of industry executives (74\%) estimated that managed care pharmacists see at least three PSRs per week. In contrast, $70 \%$ of the pharmacists indicated that they see two or fewer PSRs each week. The opinions of the two groups were not significantly different as to whether the frequency of PSR calls was acceptable; however, it should be recognized
Figure 1. Estimate of number of PSR calls on managed care pharmacists. Significant differences between pharmacists and executives at $p<0.0001$.

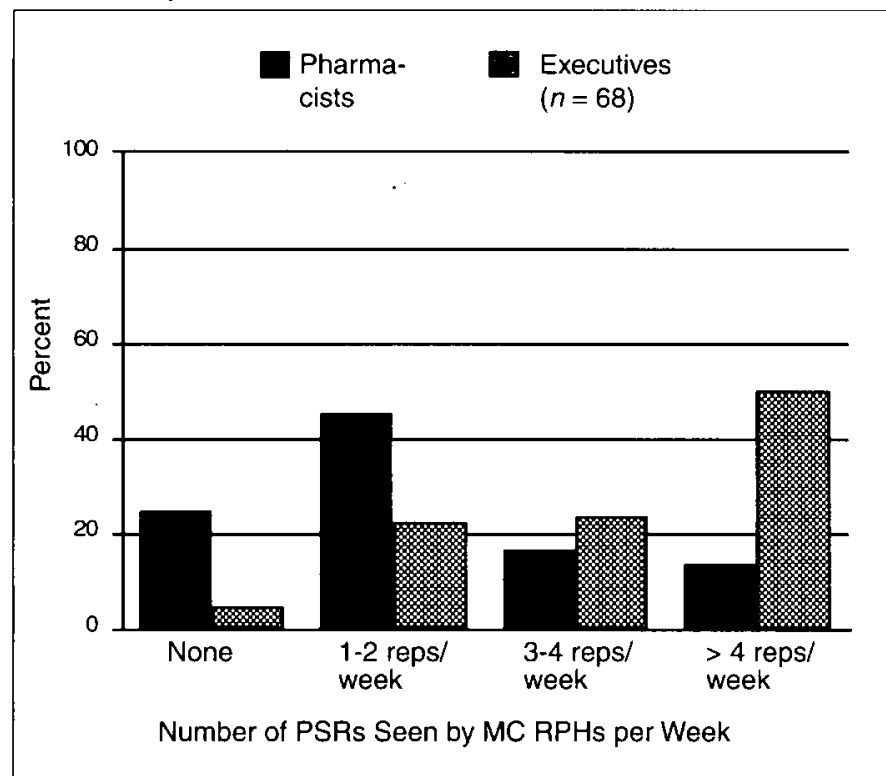

Figure 2. Opinions about frequency of PSR calls on managed care pharmacists. Differences between pharmacists and executives not significant $(p=0.082)$.

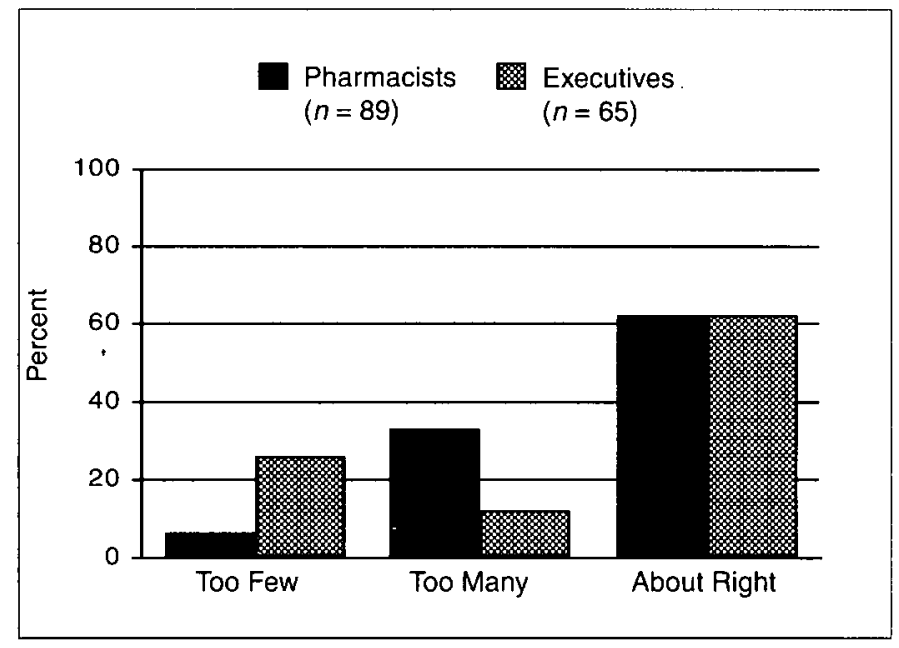

that most pharmacist opinions were based on a frequency of two or fewer PSR calls per week while industry executive opinions were based on an estimated three or greater calls per week.

Pharmacists and industry executives also differed in their opinions of how often PSRs should see managed care physicians. As shown in Figure 3, 70\% of the industry executives felt that PSRs do not call on managed care physicians often enough. In contrast, pharmacists felt that PSRs visit physicians too frequently (32\%), the number of visits was about right (33\%), or they should not interact with the physicians at all (31\%).

When questioned about which type of representative 
Figure 3. Opinions about frequency of PSR calls on managed care phyisicans. Significant differences between pharmacists and executives at $p=0.006$.

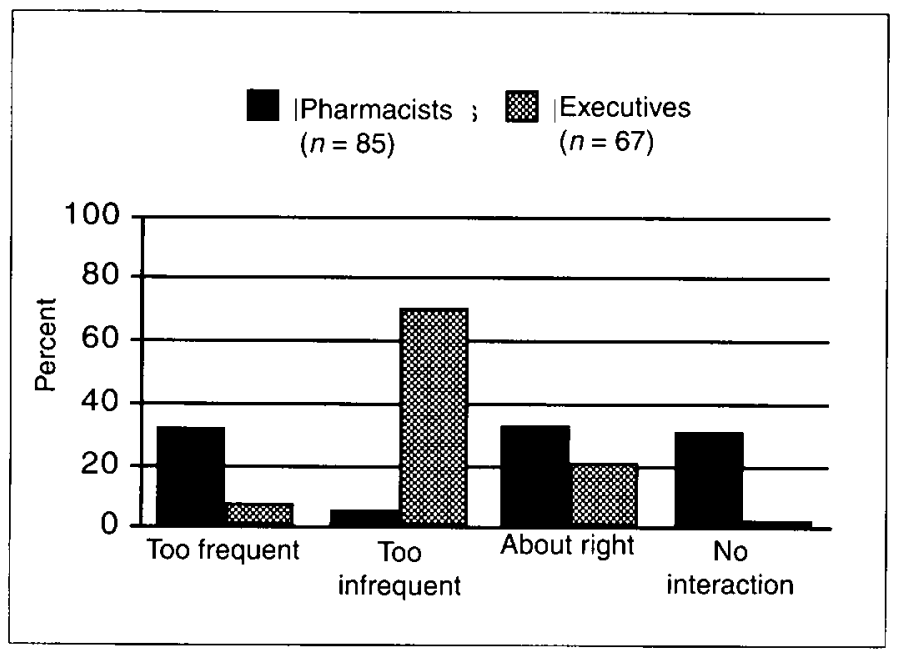

should call on managed care physicians, $90 \%$ of industry executives would prefer traditional representatives. Pharmacists were in clear disagreement, with only $29 \%$ supporting the use of traditional representatives for this purpose.

\section{Support Services and Benefits Provided by} Pharmaceutical Companies of the 13 support services/benefits described in Table 4, only four were rated significantly different by managed care pharmacists and industry executives as to their level of importance to managed healthcare professionals. Industry executives felt the following three services were more important than did managed care pharmacists:

$\boldsymbol{\nabla}$ Pharmacoeconomic and outcomes educational programs

$\boldsymbol{\nabla}$ Money back guarantees

$\boldsymbol{\nabla}$ Software for cost evaluations

Conversely, managed care pharmacists felt that providing "patient educational materials and patient package inserts" was of greater importance than did industry executives.

\section{CONCLUSION}

Managed care pharmacists and industry executives were in agreement on many issues explored in this study. Both groups generally agreed on the types of research needed and which PSR services and company support services were most and least important

Based on the importance ratings, pharmaceurical companies should ensure that their representatives are able to participate in negotiating contracts, provide support for continuing education programs, and continue to provide scientific information about new drugs. PSR distribution of information on established drugs is less important to pharmacists than to industry executives. Both groups believed strongly that drug sampling be discontinued.

Both groups also agreed that the "traditional" sales representative was not the appropriate type of representative to interact with managed care pharmacists. Responses to open-ended questions indicate that managed care pharmacists do not like the promotional style associated with traditional representatives (e.g., the "hard sell, biased sales pitch, free gifts, and meals") and the inherent pressure accompanying this style. While industry executives agreed that traditional PSRs should not call on pharmacists, they strongly supported the traditional PSR interacting frequently with managed care physicians. Pharmaceutical companies must be alert to a potential conflict with managed care pharmacists regarding frequent detailing of managed care physicians by traditional PSRs.

The results of this study should be beneficial to managed care pharmacists in better explaining their needs to the pharmaceutical industry. In addition, the information may be valuable to pharmaceutical companies as they revamp their business and marketing support services and plan their marketing and research budgets.

\section{$\checkmark$}

1. Marion Merrell Dow managed care digest, HMO edition. Kansas City, MO: Marion Merrell Dow Inc., 1994:4.

2. Marion Merrell Dow managed care digest, PPO edition. Kansas City, MO: Marion Merrell Dow
Inc., 1994:4.

3. Wechsler J. A tough year for the pharmaceutical industry. Pharm Exec 1993;1.3(Dec):20, 22, 24.

4. Santell JP, Birdwell SW, Scheckelhoff DJ. Per- ception of the role of medical-service representatives in hospitals. Am J Hosp Pharm 1990:47:1354-9. 